\title{
The effect of rehabilitation support on male and female after intertrochanteric femoral fracture treatment
}

\author{
(D)Betül Başar \\ University of Health Sciences, Gaziosmanpaşa Training and Research Hospital, Department of Physical Medicine and Rehabilitation, İstanbul, \\ Turkey
}

Cite this article as: Bașar B. The effect of rehabilitation support on male and female after intertrochanteric femoral fracture treatment. J Health Sci Med 2022; 5(1): 32-37.

\begin{abstract}
Aim: The aim of our study is to investigate the effect of rehabilitation support after intertrochanteric femur fractures on men and women. The results of the groups consisting of male and female patients who received and did not receive rehabilitation support were compared both between the same sexes and between different sexes.

Material and Method: One hundred twenty four patients were evaluated under two groups according to whether they received rehabilitation support or not. First group (no rehabilitation support) consists of 42 females, and 29 males, and second group (rehabilitation support) consists of 30 females, and 23 males. While the patients in the first group performed the exercises themselves at home, the patients in the second group received rehabilitation support under the guidance of a physiotherapist. The patients in both groups were also evaluated under 2 subgroups as male and female.

Results: There was no significant differences between both groups in terms of mean age, female male ratio, fracture type, mean follow-up time, Harris hip score, Barthel life index, Parker and Palmer Mobility Scale before fracture. There was also no significant difference between the subgroups of the both groups. Harris hip score, Barthel life index, and Parker and Palmer Mobility Score of males were better than females at the final follow-up in the first group. The results of females were worse than pre-fracture, but there was no difference in males at the final follow-up. Harris hip score, Barthel life index, and Parker and Palmer Mobility Score of males were better than females at the final follow-up in the second group as first group. While the results of females were not different compared to pre-fracture, the results were better in males at the final follow-up. When the female and male subgroups of both groups were compared with each other, it was determined that the results in male and female subgroups in the 2nd group were significantly better.

Conclusion: The continuity of rehabilitation support after hospital discharge is very important. Although rehabilitation support positively affects the results in male and female, it is much more important for female than male.
\end{abstract}

Keywords: Intertrochanteric femural fracture, rehabilitation support, functional results

\section{INTRODUCTION}

Intertrochanteric femural fracture is one of the most common proximal femoral injuries in the elderly population (1). The comorbidities such as decreased bone mineral density, physical functional insufficiency, undernutrition, cognitive impairment, and vision problems increase risk of intertrochanteric femur fracture at elderly patients (2). The life expectancy of the population has increased in the last decade. Intertrochanteric femur fracture has become an important health problem with the increase in the elderly population (1).

Mortality and morbidity increase if patients remain bedridden for a long time after intertrochanteric femural fracture. Prolonged immobilization causes morbidities like pressure ulcer, urinary tract infection, and respiratory tract infection. Early mobilization and rehabilitation play an important role in preventing these complications (3).

Surgical treatment is the best option in intertrochanteric femural fracture (4). Stable fixation should be provided with the implants. The patients should be mobilized in the early postoperative period. (5). Early mobilization and rehabilitation are started under the guidance of a physiotherapist. This process does not exceed 7-10 days. While some patients do not receive rehabilitation support, some patients continue their rehabilitation under the guidance of a physiotherapist after hospital discharge. 
The aim of our study is to investigate the effect of rehabilitation support after intertrochanteric femur fractures on men and women. The results of the groups consisting of male and female patients who received and did not receive rehabilitation support were compared both between the same sexes and between different sexes.

\section{MATERIAL AND METHOD}

This retrospective, clinical trial was approved by the Clinical Researchs Ethics Committee of Gaziosmanpaşa Training and Research Hospital (Date: 17.03.2021, Decision No: 2021-227) and was performed in accordance with the tenets of the Declaration of Helsinki (6). All methods were performed following the relevant guidelines and regulations. After informing the patients about the possible side effects of the treatments, a written informed consent was obtained from each patient.

Thisstudy included independentlyliving intertrochanteric femoral fracture patients, over 70 years of age, who were surgically treated in January 2014 and January 2019. The patients were operated within 10 days after injury. The exclusion criterias were inability to reach the patient, death of the patient, a history of the other side proximal femoral fracture, additional fractures, and pathologic fractures. The fracture type was evaluated according to AO classification (7). 31.A1 and 31.A2 type fractures were included in our study.

The patients included in the study were found by scanning the hospital archive, which has been kept regularly since the beginning of 2014. Patients with missing data were not evaluated. Two hundred seventy five patients were evaluated retrospectively from the hospital archive. Onehundred fifty-one patients were not included in our study. 72 patients could not be reached, 32 patients did not come to the last follow-up, 30 patients had additional fractures in their lower extremities, 12 patients had a history of proximal femur fracture on the contralateral side, and 5 patients had pathological fractures. Onehundred and twenty-four patients were included in our study. At the time of fracture, all patients were either living in their own home or in some sort of community housing comparable to their own home. They had either fully independent or partially assisted lifestyles. All patients were independently mobilized without assistive device. The patients were evaluated under two groups according to whether they received rehabilitation support under the guidance of a physiotherapist hospital discharge. Group 1 (No Rehabilitation Support) consists of 42 females, and 29 males, and group 2 (Rehabilitation Support) consists of 30 females, and 23 males. The patients were called to the hospital to perform control examinations and radiological evaluations.
Rehabilitation was initiated under the guidance of a physiotherapist on the first day after surgery for the patients in both groups. Rehabilitation continued until hospital discharge. The mean hospital discharge time was $5.39 \pm 2.70$ days in group 1 and $5.58 \pm 2.69$ days in group 2. Informative brochures were given to the patients at discharge for the continuity of rehabilitation. The patients in first group did not receive rehabilitation support and tried to do their exercises themselves. The patients in the 2nd group received rehabilitation support under the guidance of a physiotherapist in a nursing home or in their own homes.

All patients received the same rehabilitation support that was started at the end of 2013. This rehabilitation support was applied in the same way to all patients who were operated for hip fracture in the Orthopaedics and Traumatology service. Rehabilitation support was implemented to include the following: strengthening exercises mainly for hip flexors, extensors, abductors, and knee extensors; range-of-motion (ROM) exercises, mainly for the hip joint; balance training; functional training such as sit-to-stand training, ambulation training, and stair climbing; practice of safe and efficient transfer techniques; adjustment of walking aids; and adaptation and modification of the living area. The exercises were applied according to the individual capacity and general condition of each patient. Two times a day for 10 repetitions for each item were performed. The number of repetitions and sets was increased if the patients tolerated these exercises under the guidance of a physiotherapist. $0.5-1 \mathrm{~kg}$ sandbags were used as resistance according to the individual capacity of each patient. If the patients had any discomfort during rehabilitation, rehabilitation was suspended. Rehabilitation support was continued for 3 months.

The pre-fracture Harris Hip Score, Barthel Life Index, Parker and Palmer Mobility Score of the patients were calculated with the forms filled in verbally when the patients were admitted to the hospital due to the fracture. These informations were obtained from hospital records. The values at the last controls were not taken from the hospital records. The same physiotherapist calculated these scores by calling the patients for control. Fracture healing was controlled by direct radiography at final follow-up. Evaluation of the patients was made according to the Harris Hip Score for clinically, Barthel Life İndex for daily life activities and Parker and Palmer Mobility Score for mobilization by the same physiotherapist in Gaziosmanpaşa Training and Research Hospital at final follow-up (8-10).

\section{Statistical Analysis}

The data were compared using Student's unpaired $t$ test/ Mann-Whithey test for quantitative measurements, 
and Chi-square test/Fischer exact test for qualitative measurements. A p value below 0.05 was considered significant. The data were entered in MS Excel spread sheet,and statistical analysis was done using Statistical Package for Social Seciences (SPSS) version 16.0.

\section{RESULTS}

\section{Comparison of Male and Female in Group 1 (No Rehabilitation Support)}

In the pre-fracture evaluation; forty-two females for an average of $25.42 \pm 8.41$ months and 29 males for a mean of $27.68 \pm 9.66$ months were evaluated. There was no statistically significant difference between males and females in terms of mean age, follow-up time, and fracture type according to AO classification ( $\mathrm{p}>0.05)$ (Table 1).

The Harris hip score of females was poor in 20, moderate in 12, good in 7, and excellent in 3. Eight had poor, 12 had moderate, 7 had good, and 2 had excellent results in males. Nine patients were independent, 28 patients were minimally dependent, and 5 patients were partially dependent according to the Barthel life index in females. Six patients were independent, 22 patients were minimally dependent, and 1 patient was partially dependent in males. The mean value was $6.38 \pm 1.22$ in females and $6.82 \pm 1.07$ in males according to Parker and Palmer Mobility Score (Table 1). There was no statistically significant difference between males and females in terms of Harris hip score, Barthel life index and Parker and Palmer Mobility Scale at pre-fracture period $(\mathrm{p}>0.05)$, (Table 1).

In the last follow-up evaluation; the Harris hip score of females was poor in 38, good in 3 , and excellent in 1 . Sixteen had poor, 6 had moderate, 6 had good, and 1 had excellent results in males. Two patients were independent, 9 patients were minimally dependent, 22 patients were partially dependent, 8 patients were very dependent, and 1 patient were totally dependent according to the Barthel life index in females. Four patients were independent, 17 patients were minimally dependent, and 8 patient was partially dependent in males. The mean value was $5.42 \pm 1.67$ in females and $6.72 \pm 0.88$ in males according to Parker and Palmer Mobility Score. (Table 1). There were statistically significant differences between males and females in terms of Harris hip score, Barthel life index, and Parker and Palmer Mobility Scale at last follow-up in the first group $(\mathrm{p}<0,05)$, (Table 1$)$. The result was better in males. Harris hip score, Barthel life index and Parker and Palmer Mobility Scale results in the last follow-up were compared with the pre-fracture results. The results were statistically significantly worse in females at the last follow-up ( $\mathrm{p}<0.05)$. There was no statistically significant difference between the final follow-up results and prefracture results in males $(\mathrm{P}>0.05)$, (Table 1).

\section{Comparison of Males and Females in Group 2 (Rehabilitation Support)}

In the pre-fracture evaluation; the mean followup period was $27.60 \pm 12.06$ months in females and $30.43 \pm 12.10$ months in males in the second group (Rehabilitation Support). There was no statistically significant difference between males and females in terms of mean age, follow-up time, and fracture types according to AO classification ( $\mathrm{p}>0.05$ ) (Table 2).

\begin{tabular}{|c|c|c|c|}
\hline $\begin{array}{l}\text { Non-rehabilitation } \\
\text { group }\end{array}$ & $\begin{array}{l}\text { Female } \\
\text { (No:42) }\end{array}$ & $\begin{array}{c}\text { Male } \\
(\text { No:29) }\end{array}$ & $\mathbf{P}$ \\
\hline Mean Age & $76.25 \pm 4.84$ & $77.24 \pm 4.71$ & 0.3928 \\
\hline $\begin{array}{l}\text { Mean Follow-up } \\
\text { Period (month) }\end{array}$ & $25.42 \pm 8.41$ & $27.68 \pm 9.66$ & 0.3119 \\
\hline AO Classification & & & 0.6220 \\
\hline A1 & 24 & 19 & \\
\hline A2 & 18 & 10 & \\
\hline $\begin{array}{l}\text { Operation Period } \\
\text { (day) }\end{array}$ & $5.61 \pm 2.71$ & $5.06 \pm 2.71$ & 0.4042 \\
\hline $\begin{array}{l}\text { Pre-operative Harris } \\
\text { Hip Score }\end{array}$ & $70.30 \pm 11.50$ & $74.34 \pm 10.29$ & 0.0955 \\
\hline $\begin{array}{l}\text { Follow-up Harris Hip } \\
\text { Score }\end{array}$ & $50.69 \pm 15.36$ & $68.86 \pm 11.92$ & $<0.0001$ \\
\hline $\mathrm{P}$ & $<0.0001$ & 0.0737 & \\
\hline $\begin{array}{l}\text { Pre-operative Barthel } \\
\text { Life Index }\end{array}$ & $68.69 \pm 12.10$ & $72.58 \pm 8.19$ & 0.0861 \\
\hline $\begin{array}{l}\text { Follow-up Barthel } \\
\text { Life Index }\end{array}$ & $49.76 \pm 15.57$ & $66.72 \pm 11.36$ & $<0.0001$ \\
\hline $\mathrm{P}$ & $<0.0001$ & 0.0671 & \\
\hline $\begin{array}{l}\text { Pre-operative Parker } \\
\text { Palmer Mobility Score }\end{array}$ & $6.38 \pm 1.22$ & $6.82 \pm 1.07$ & 0.1194 \\
\hline $\begin{array}{l}\text { Follow-up Parker } \\
\text { Palmer Mobility Score }\end{array}$ & $5.42 \pm 1.67$ & $6.72 \pm 0.88$ & 0.0007 \\
\hline $\mathrm{P}$ & 0.0103 & 0.6320 & \\
\hline
\end{tabular}

\begin{tabular}{|c|c|c|c|}
\hline Rehabilitation group & $\begin{array}{l}\text { Female } \\
(\text { No:30) }\end{array}$ & Male (No:23) & $\mathbf{P}$ \\
\hline Mean age & $78.23 \pm 6.09$ & $76.60 \pm 5.75$ & 0.3260 \\
\hline $\begin{array}{l}\text { Mean follow-up } \\
\text { period (month) }\end{array}$ & $27.60 \pm 12.06$ & $30.43 \pm 12.10$ & 0.4016 \\
\hline AO classification & & & 0.7750 \\
\hline A1 & 20 & 14 & \\
\hline A2 & 10 & 9 & \\
\hline $\begin{array}{l}\text { Operation period } \\
\text { (day) }\end{array}$ & $5.40 \pm 2.94$ & $5.82 \pm 2.38$ & 0.5633 \\
\hline $\begin{array}{l}\text { Pre-operative } \\
\text { Harris hip score }\end{array}$ & $72.90 \pm 13.68$ & $71.78 \pm 14.03$ & 0.8435 \\
\hline $\begin{array}{l}\text { Follow-up } \\
\text { Harris hip score }\end{array}$ & $74.46 \pm 13.72$ & $82.13 \pm 13.80$ & 0.0381 \\
\hline$P$ & 0.6150 & 0.0108 & \\
\hline $\begin{array}{l}\text { Pre-operative } \\
\text { Barthel life index }\end{array}$ & $71.66 \pm 15.27$ & $70.86 \pm 12.40$ & 0.8014 \\
\hline $\begin{array}{l}\text { Follow-up } \\
\text { Barthel life index }\end{array}$ & $68.00 \pm 14.77$ & $77.39 \pm 13.30$ & 0.0173 \\
\hline $\mathrm{P}$ & 0.4156 & 0.0429 & \\
\hline $\begin{array}{l}\text { Pre-operative Parker } \\
\text { Palmer mobility score }\end{array}$ & $6.63 \pm 1.06$ & $6.47 \pm 1.27$ & 0.5401 \\
\hline $\begin{array}{l}\text { Follow-up Parker } \\
\text { Palmer mobility score }\end{array}$ & $6.76 \pm 1.22$ & $7.47 \pm 1.37$ & 0.0305 \\
\hline $\mathrm{P}$ & 0.4311 & 0.0124 & \\
\hline
\end{tabular}


The Harris hip score of females was poor in 13, moderate in 6 , good in 7 , and excellent in 4 . Ten had poor, 5 had moderate, 5 had good, and 3 had excellent results in males. Thirteen patients were independent, 11 patients were minimally dependent, and 6 patients were partially dependent according to the Barthel life index in females. Nine patients were independent, 12 patients were minimally dependent, and 2 patients were partially dependent in males. The mean value was $6.63 \pm 1.06$ in female and $6.47 \pm 1.27$ in male according to Parker and Palmer Mobility Score (Table 2). There was no statistically significant difference between the second group males and females in terms of Harris hip score, Barthel life index and Parker and Palmer mobility scale at pre-fracture period ( $p>0,05)$ (Table 2).

In the last follow-up evaluation; the Harris hip score of females was poor in 11 , moderate in 8 , good in 6 , and excellent in 5. Three had poor, 4 had moderate, 9 had good, and 7 had excellent results in males. Thirteen patients were independent, 11 patients were minimally dependent, and 6 patients were partially dependent according to the Barthel life index in females. Nine patients were independent, 12 patients were minimally dependent, and 2 patients was partially dependent in males. The mean value was $6.76 \pm 1.22$ in female and $7.47 \pm 1.37$ in male according to Parker and Palmer Mobility Score (Table 2). There were statistically significant differences between the second group males and females in terms of Harris hip score, Barthel life index and Parker and Palmer mobility scale at last follow-up $(\mathrm{p}<0,05)$ (Table 1). Better results were obtained in males. Harris hip score, Barthel life index and Parker and Palmer mobility scale results in the final follow-up were compared with the pre-fracture results. There was no statistically significant difference between the final follow-up results and pre-fracture results in females ( $\mathrm{P}>0.05)$, (Table 2). The results were statistically significantly better in males at the last follow-up $(\mathrm{p}<0.05)$.

\section{Comparison of Females in Group 1 and Group 2}

There was no statistically significant difference between group 1 and group 2 females in terms of mean age, follow-up time, fracture types according to $\mathrm{AO}$ classification, pre-fracture Harris hip score, Barthel life index and Parker and Palmer Mobility Scale ( $>>0.05)$, (Table 3).

Statistically significantly better results were obtained in Group 2 females in the final follow-up ( $>>0.05$ ) (Table 3).

\section{Comparison of Males in Group 1 and Group 2}

There was no statistically significant difference between group 1 and group 2 males in terms of mean age, follow-up times, and fracture types according to $\mathrm{AO}$ classification, pre-fracture Harris hip score, Barthel life index and Parker and Palmer Mobility Scale ( $p>0.05)$, (Table 4).

Statistically significantly better results were obtained in Group 2 males in the final follow-up. ( $p>0.05)$, (Table 4).

\begin{tabular}{|lccc|}
\hline $\begin{array}{l}\text { Table 3. Female patient characteristics, functional scores, and } \\
\text { mobility scores in both group }\end{array}$ & $\begin{array}{c}\text { Non- } \\
\text { rehabilitation } \\
\text { group (No:42) }\end{array}$ & $\begin{array}{c}\text { Rehabilitation } \\
\text { group } \\
\text { (No: } 30)\end{array}$ & P \\
\hline $\begin{array}{l}\text { Mean age } \\
\begin{array}{l}\text { Mean follow-up } \\
\text { period (month) }\end{array}\end{array}$ & $25.42 \pm 8.41$ & $27.60 \pm 12.06$ & 0.3999 \\
AO classification & 24 & $78.23 \pm 6.09$ & 0.0923 \\
\multicolumn{1}{|c}{ A1 } & 18 & 10 & 0.4688 \\
$\quad$ A2 & $5.61 \pm 2.71$ & $5.40 \pm 2.94$ & 0.7489 \\
$\begin{array}{l}\text { Operation period } \\
\text { (day) }\end{array}$ & $70.30 \pm 11.50$ & $72.90 \pm 13.68$ & 0.4646 \\
$\begin{array}{l}\text { Pre-operative Harris } \\
\text { hip score }\end{array}$ & $50.69 \pm 15.36$ & $74.46 \pm 13.72$ & $<0.0001$ \\
$\begin{array}{l}\text { Follow-up Harris hip } \\
\text { score }\end{array}$ & $68.69 \pm 12.10$ & $71.66 \pm 15.27$ & 0.4137 \\
$\begin{array}{l}\text { Pre-operative } \\
\text { Barthel life index }\end{array}$ & $49.76 \pm 15.57$ & $68.00 \pm 14.77$ & $<0.0001$ \\
$\begin{array}{l}\text { Follow-up } \\
\text { Barthel life index }\end{array}$ & $6.38 \pm 1.22$ & $6.63 \pm 1.06$ & 0.4387 \\
$\begin{array}{l}\text { Pre-operative Parker } \\
\text { Palmer mobility score }\end{array}$ & $5.42 \pm 1.67$ & $6.76 \pm 1.22$ & 0.0007 \\
$\begin{array}{l}\text { Follow-up Parker } \\
\text { Palmer mobility score }\end{array}$ & & & \\
\hline
\end{tabular}

Table 4. Male patient characteristics, functional scores, and mobility scores in both group

\begin{tabular}{|c|c|c|c|}
\hline Male & $\begin{array}{l}\text { Non- } \\
\text { rehabilitation } \\
\text { group (No:29) }\end{array}$ & $\begin{array}{l}\text { Rehabilitation } \\
\text { group } \\
\text { (No: 23) }\end{array}$ & $\mathbf{P}$ \\
\hline Mean age & $77.24 \pm 4.71$ & $76.60 \pm 5.75$ & 0.6724 \\
\hline $\begin{array}{l}\text { Mean follow-up } \\
\text { period (month) }\end{array}$ & $27.68 \pm 9.66$ & $30.43 \pm 12.10$ & 0.3805 \\
\hline AO classification & & & 0.7778 \\
\hline A1 & 19 & 14 & \\
\hline A2 & 10 & 9 & \\
\hline $\begin{array}{l}\text { Operation period } \\
\text { (day) }\end{array}$ & $5.06 \pm 2.71$ & $5.82 \pm 2.38$ & 0.2901 \\
\hline $\begin{array}{l}\text { Pre-operative } \\
\text { Harris hip score }\end{array}$ & $74.34 \pm 10.29$ & $71.78 \pm 14.03$ & 0.5430 \\
\hline $\begin{array}{l}\text { Follow-up } \\
\text { Harris hip score }\end{array}$ & $68.86 \pm 11.92$ & $82.13 \pm 13.80$ & 0.0003 \\
\hline $\begin{array}{l}\text { Pre-operative } \\
\text { Barthel life index }\end{array}$ & $72.58 \pm 8.19$ & $70.86 \pm 12.40$ & 0.9119 \\
\hline $\begin{array}{l}\text { Follow-up } \\
\text { Barthel life index }\end{array}$ & $66.72 \pm 11.36$ & $77.39 \pm 13.30$ & 0.0017 \\
\hline $\begin{array}{l}\text { Pre-operative Parker } \\
\text { Palmer mobility score }\end{array}$ & $6.82 \pm 1.07$ & $6.47 \pm 1.27$ & 0.2330 \\
\hline $\begin{array}{l}\text { Follow-up Parker } \\
\text { Palmer mobility score }\end{array}$ & $6.72 \pm 0.88$ & $7.47 \pm 1.37$ & 0.0072 \\
\hline
\end{tabular}




\section{DISCUSSION}

The life expectancy of the general population is increased significantly in the past decades. The prevalence of proximal femur fractures and particularly intertrochanteric femoral fractures increases as the quality of bone decreases with age (11).

The success of the surgical treatment and the union of the fracture after fixation are not sufficient for the successful clinical results. Rehabilitation and early mobilization are very important for clinical results. The success in the functional results is significantly related with the ambulatory ability (12). Therefore, mobilization and rehabilitation support is very important to increase the mobilization capacity in the early period (3).

The proximal femoral nail was a treatment choice for intertrochanteric femoral fracture. Rehabilitation and mobilization can be started immediately after surgery (13). Therefore, we preferred proximal nail in the surgical treatment of our patients.

Hospital-based rehabilitation positively affects functional results. However, the high cost of hospitalbased rehabilitation is a problem (14). Nowadays, hospital stays are not long enough for rehabilitation due to high costs. Therefore, rehabilitation support plays an important role after hospital discharge. Post-hospital rehabilitation includes a rehabilitation facility, a skilled nursing facility, and home-based physical therapy (15). There was no significant difference between hospitalbased therapy and home-based therapy at 12-month follow-up. Only hospital-based therapy gives better results in terms of upper extremity motor strength (16).

Functional results were better in patients who received rehabilitation support in the study of Lahtinen et al. (14). Functional outcomes are expected to be better in arthroplasty than in osteosynthesis with intramedullary nail or plate screws (17). The results of males and females were not compared in these studies (14).

The effect of rehabilitation on hip fracture was evaluated in a study conducted by Lieberman et al. However, the study included a heterogeneous patient group with different hip fractures and different treatment options. While arthroplasty was applied to some of the patients, osteosynthesis was applied to the others. No research has been conducted on patients who do not receive rehabilitation support (18).

Magazine et al. compared two different rehabilitation support after hip fracture. A homogeneous patient group was also not included in this study. The patients with different hip fractures and different treatment options were included in the study. The effect of gender on the results has not been studied. It was determined that the effect of two different rehabilitation supports on the results was not different (19).

The patients were not evaluated in homogeneous groups in these studies investigating the effect of rehabilitation on hip fractures. Our study was conducted on a homogeneous group. There is no study in the literature on the effect of rehabilitation in patients who underwent proximal nailing for intertrochanteric femoral fractures. We compared the results of patients who received rehabilitation support and those who did not, and the effect of whether there was rehabilitation support in male and female patients.

\section{CONCLUSION}

It was found that rehabilitation support affects the results positively in intertrochanteric femoral fractures fixed with a proximal femoral nail in our study. Although rehabilitation support was not applied in males, it was determined that pre-fracture functional values were reached in the final follow-up. Pre-fracture functional results could not be achieved in females who did not receive rehabilitation support at the final follow-up. Lack of rehabilitation support negatively affects outcomes in females. On the other hand, the results were much better than before fractures in males who received rehabilitation support. Rehabilitation support is very important for both females and males. Even if rehabilitation is not applied to male patients, they regain their previous functional capacity. If post-surgical rehabilitation is not applied, the results are much worse in females. Therefore, rehabilitation should be applied after surgical treatment of intertrochanteric femoral fractures especially in females.

\section{ETHICAL DECLARATIONS}

Ethics Committee Approval: The study was approved by the Clinical Researchs Ethics Committee of Gaziosmanpaşa Training and Research Hospital (Date: 17.03.2021, Decision No: 2021-227).

Informed Consent: Because the study was designed retrospectively, no written informed consent form was obtained from patients.

Referee Evaluation Process: Externally peer-reviewed.

Conflict of Interest Statement: The authors have no conflicts of interest to declare.

Financial Disclosure: The authors declared that this study has received no financial support.

Author Contributions: All of the authors declare that they have all participated in the design, execution, and analysis of the paper, and that they have approved the final version. 


\section{REFERENCES}

1. Bäcker $\mathrm{HC}, \mathrm{Wu} \mathrm{CH}$, Maniglio $\mathrm{M}$, Wittekindt S, Hardt S, Perka C. Epidemiology of proximal femoral fractures. J Clin Orthop Trauma 2021; 12: 161-5.

2. Osteoporosis: review of the evidence for prevention, diagnosis and treatment and cost-effectiveness analysis. Executive summary. Osteoporos Int. 1998; 8: S3-S6.

3. Yoo JI, Ha YC, Lim JY, Kang H, Yoon BH, Kim H. Early rehabilitation in elderly after arthroplasty versus internal fixation for unstable intertrochanteric fractures of femur: systematic review and meta-analysis. J Korean Med Sci 2017; 32: 858-67.

4. Socci AR, Casemyr NE, Leslie MP, Baumgaertner MR. Implant options for the treatment of intertrochanteric fractures of the hip: rationale, evidence, and recommendations. Bone Joint J 2017; 99: 128-33.

5. Morri M, Forni C, Marchioni M, Bonetti E, Marseglia F, Cotti A. Which factors are independent predictors of early recovery of mobility in the older adults' population after hip fracture? A cohort prognostic study. Arch Orthop Trauma Surg 2018; 138: 35-41.

6. World Medical Association Declaration of Helsinki Ethical Principles for Medical Research Involving Human Subjects. In: Amended by $59^{\text {th }}$ WMA General Assembly, Seoul: World Medical Association; 2008.

7. Chan G, Hughes K, Barakat A, et al. Inter- and intra-observer reliability of the new AO/OTA classification of proximal femur fractures. Injury 2021; 52: 1434-7.

8. Harris WH. Traumatic arthritis of the hip after dislocation and acetabular fractures: treatment by mold arthroplasty. An endresult study using a new method of result evaluation. J Bone Joint Surg Am 1969; 51: 737-55.

9. Mahoney FI, Barthel DW. Functional evaluation: the Barthel index. Md State Med J 1965; 14: 61

10. Çiloğlu O, Karaali E, Kuşvuran Özkan A, Ekiz T. Distally-fixed nonmodular monoblock fluted long-stem hemiarthroplasty versus proximal femoral nailing for elderly patients with an osteoporotic intertrochanteric fracture: a retrospective comparative study. Hip Int 2020; 1120700020963529.

11. Sahin S, Ertürer E, Oztürk I, Toker S, Seçkin F, Akman S. Radiographic and functional results od osteosynthesis using the proximal femoral nail antirotation (PFNA) in treatment of usnstable intertrochanteric femoral fractures. Acta Orthop Traumatol Turc 2010; 44: 127-34.

12. Chudyk AM, Jutai JW, Petrella RJ, Speechley M. Systematic review of hip fracture rehabilitation practices in the elderly. Arch Phys Med Rehabil 2009; 90: 246-62.

13. Hardy DC, Descamps PY, Krallis P, et al. Use of an intramedullary hip-screw compared with a compression hip-screw with a plate for intertrochanteric femoral fractures. A prospective, randomized study of one hundred patients. J Bone Joint Surg Am 1998; 80: 618-30.

14.Lahtinen A, Leppilahti J, Vähänikkilä $H$, et al. Costs after hip fracture in independently living patients: a randomised comparison of three rehabilitation modalities. Clin Rehabil 2017; 31: 672-85.

15. Tsauo jy, Leu WS, Chen YT, Yang RS. Effects on function and quality of life postoperative home besed physical therapy for patients with hip fracture. Arch Ohys Med Rehabil 2005; 86: 1953-7.

16. Tinetti ME, Baker DI, Gottschalk M, et al. Home-based multicomponent rehabilitation program for older persons after hip fracture: arandomized trial. Arch Phys Med Rehabil 1999; 80: 916-22.

17. Shetty SH, Dhond AB, Agarwal A, Kharat A, Singh A.
Intertrochanteric fracture of femur in elderly - A comparative analysis between hemiarthroplasty and osteosynthesis. Int J Orthop Sci 2017; 3: 449-452

18. Lieberman D, Lieberman D. Rehabilitation following hip fracture surgery: a comparative study of females and males. Disabil Rehabil 2004; 21; 26: 85-90.

19. Magaziner J, Mangione KK, Orwig D, et al. Effect of a multicomponent home-based physical therapy intervention on ambulation after hip fracture in older adults: the CAP randomized clinical trial. JAMA 2019; 322: 946-56. 